\title{
EVALUATION - A REFLECTION OF KNOWLEDGE OR A SET OF COINCIDENCES
}

\author{
Valia Dimitrova, Slavena Ilieva \\ Department of the Health Care, Faculty of Public Health, Medical University of Varna
}

\begin{abstract}
AIM: To investigate the effectiveness of the process of evaluating the knowledge and skills acquired through the eyes of students enrolled in the Midwife program.

MATERIALS AND METHODS: A survey was conducted among students in the Medical University of Varna, enrolled in the Midwife program, from $1^{\text {st }}$ to $4^{\text {th }}$ year (98 individuals). The survey is detailed and it was conducted in July, 2016. The methods used were documentary, statistical, survey, and graphical analysis.

RESULTS AND DISCUSSION: Students accept the evaluation with reservations and as a reflection of the gained throughout the studies knowledge and skills, while considering that the evaluation itself cannot be motivating for making more effort when acquiring more knowledge. They appreciate the need for systemic absorption of knowledge and application of current control in training in the Midwife program. According to them, the process of examination and evaluation does not completely eliminate the influence of random factors. It is mandatory to apply various forms, methods and tests, which can clarify the process in relation to the specifics in the practical tuition and the real life environment specifics. Students perceive the silence while someone else is cheatingm on an exam as an appropriate behavior.
\end{abstract}

CONCLUSIONS: The exam tests both the acquired knowledge and skills, and the individual qualities and character, which affect the way they present the tested/examined knowledge.

Keywords: midwife, exam, evaluation, assessment, knowledge, skills

Address for correspondence:

Valia Dimitrova

Faculty of Public Health

Medical University of Varna

55 Marin Drinov St.

Varna

e-mail:valadim@abv.bg

\section{INTRODUCTION}

In the history of pedagogy, there is growing interest in the proper assessment of the students' knowledge. In the past, the exams were also well known as initiation, catechumen, novitiate, trivium, quadrivium, in order to lead us to the, so called nowadays - exam, check, report, algorithm, control.

Among the authors, there is no consensus on all of the elements: nature, content, subject or types, methods, forms and means of verification and assessment of knowledge in tuition. Some believe that assessment is a means of determining the quality of knowledge, skills and habits of students. By testing and evaluating the acquired knowledge, students form a significant degree of self-awareness and selfassessment criteria. According to Andreev, the as- 
sessment can perform the following functions: diagnostic, informative, didactic, motivational, predictive, and selective.

There are different forms of knowledge and different approaches to their testing such as fertility, productivity and creative application of knowledge and skills. In recent years, the preferred method of examining the acquired knowledge is the test. There is no other method with which the strict requirements of objectivity, reliability, validity can be introduced. Special procedures have been developed in order to check the quality of the test.

\section{RESULTS}

Examining the effiency of the process of testing and evaluation of the acquired knowledge and skills was important in order to understand what the attitude of students towards it is. We asked them whether they think the assessment received by the student is a reflection of their actual knowledge (Fig. 1).

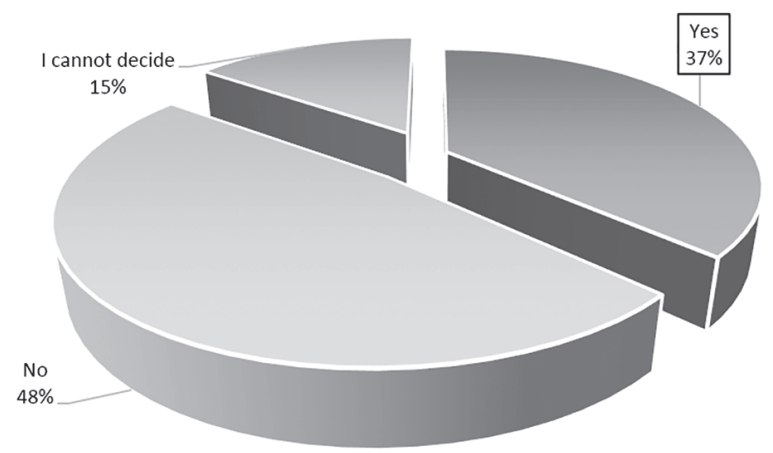

Fig. 1. Evaluation - a reflection of knowledge

Almost $1 / 2$ of the inquired respond negatively (48.15\%), and about $1 / 6$ of the students show hesitation (14.81\%). Only $1 / 3$ of the inquired think that the received assessment is a reflection of their actual knowledge (37.04\%). The response of students means that they accept with reservations the assessment as a reflection of knowledge and skills received during the course of the study.

In order to clarify how the opinions and attitudes of students towards the assessment process were formed, it was important for us to understand what the most appropriate methods and means for testing the acquired knowledge and skills are. We asked them how they prefer to be tested (Fig. 2).

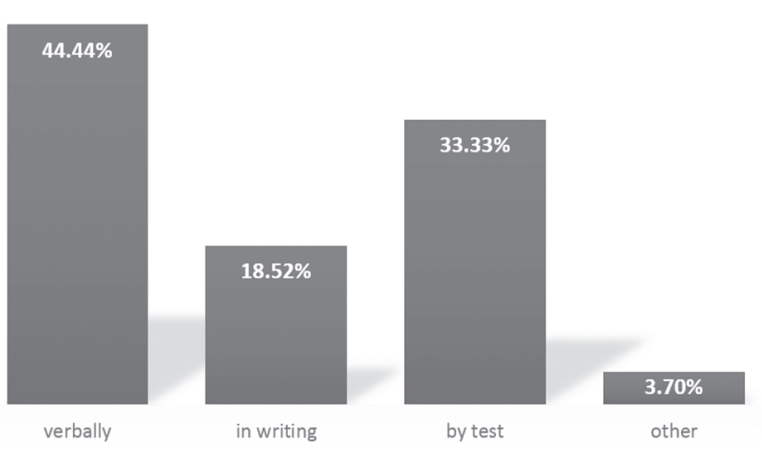

Fig. 2. Preferred test methods

Almost half of the respondents indicated preference in oral presentation on a given topic (44.44\%) and slightly more than $1 / 3$ - multiple choice type of a test (33.33\%). Less than $1 / 5$ of the students prefer free-form writing to verify their knowledge and skills. The opinion of students is not clear and probably indicates that the verification process of knowledge is influenced by many factors - the type of nervous system, nature, individual characteristics, random events, etc., and not only from the knowledge gained in the process of learning and self-study.

Until recently, an oral presentation of knowledge was the most popular in the verification of knowledge. It has a number of advantages - it involves eye contact, personal impression and attitude, allows the clarification of inaccuracies and timely correction of errors. With this type of testing knowledge, there is a certain amount of stress involved, less time to focus, the subjective factors influence both the tested individual and the testing person. We asked the students whether they thought that during an oral presentation, the examiner is influenced by the attitude of the student and his charm (Fig. 3).

Students' opinion is divided almost equally between the three versions of the answer - about $1 / 3$ consider that the behavior and charm of student influence the examiner (37.04\%), another $1 / 3$ say that this is irrelevant (37.04\%). The rest expressed hesitation (25.92\%). This response probably means ythat a variety of forms and methods have to be applied while testing, in order to objectify the process of testing itself and evaluate the acquired knowledge and skills correctly.

In our country, the educational system has adopted a six-point scale of knowledge assessment. On 


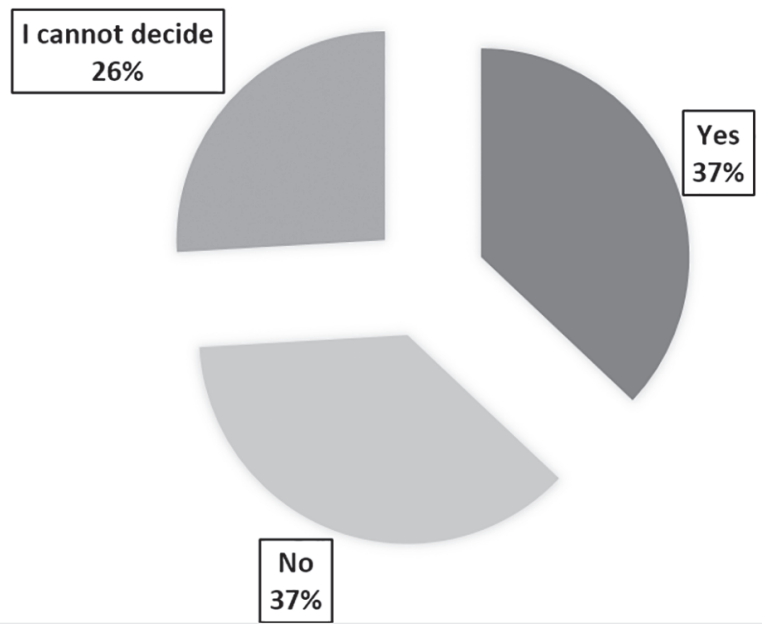

Fig. 3. Influence the behavior and the charm of student

the one hand, it is known and allows continuity and a smooth transition from high school to university. On the other - its application for assessment of practical skills and habits has its own peculiarities and specifics. We asked students whether they thought that the six-point system is adequate for knowledge assessment in the Midwife program (Fig. 4).

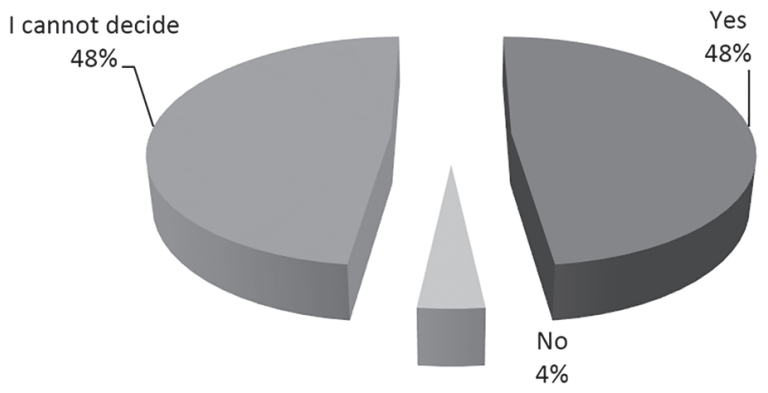

Fig. 4. Adequacy of the six-point system

Almost half of the respondents consider the sixpoint scale adequate (48.15\%) and an equal amount cannot decide (48.15\%). The relatively high share of fluctuating respondents can be interpreted in another way - that students understand the specifics of practical training and act with responsibility and criticism towards the peculiarities of working in a real working environment.

Continuous assessment during the semester is a prerequisite for deeper and purposeful utilization of the knowledge, it reduces stress during the exam pe- riod and leads to better results. We sought the views of the students on the need for ongoing testing of the various disciplines while training in the Midwife program (Fig. 5).

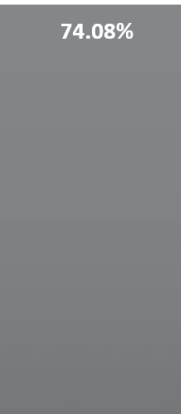

Yes

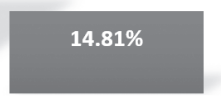

No

\section{$11.11 \%$}

I cannot decide
Fig. 5. Need for current control during the semester

The majority of respondents believe that the current control is actually useful and necessary (74.08\%). Negligible proportion of students consider it unnecessary (14.81\%), or cannot decide (11.11\%). The students' opinion reaffirms the responsibility with which they approach studying in the Midwife program at the Medical University of Varna.

For us it was interesting to understand how the performance levels of knowledge and skills of students are influenced by random events perceived, according to the Bulgarian mentality, as chance or luck. We asked students whether they have ever relied on luck during the test (Fig. 6).

More than a half of the respondents admit that they have relied on chance during exams (62.96\%), and about $1 / 4$ never trusted their luck (25.93\%). The students' response means that on one hand, they

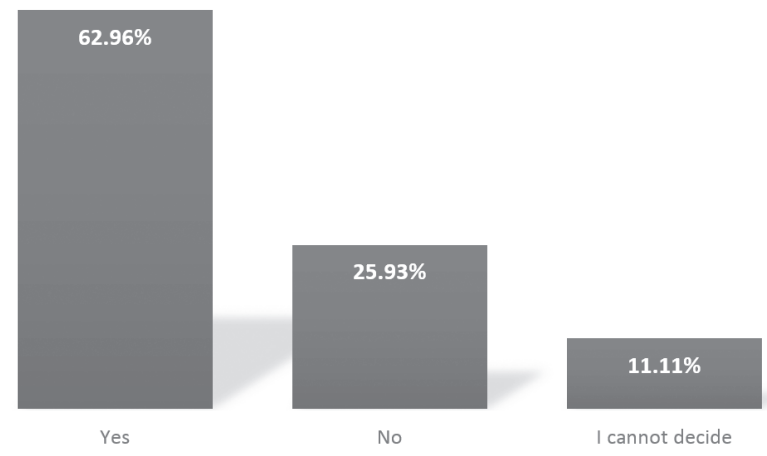

Fig. 6. Luck in exam 
mainly rely on coincidence and on the other hand the forms and methods of examination and knowledge assessment do not eliminate the influence of random facts completely.

It was interesting whether the lower grade can be a motivating factor for the increase in the students' activity and creativity. We asked them whether they think the lower grade is actually a motivator for the student (Fig. 7).
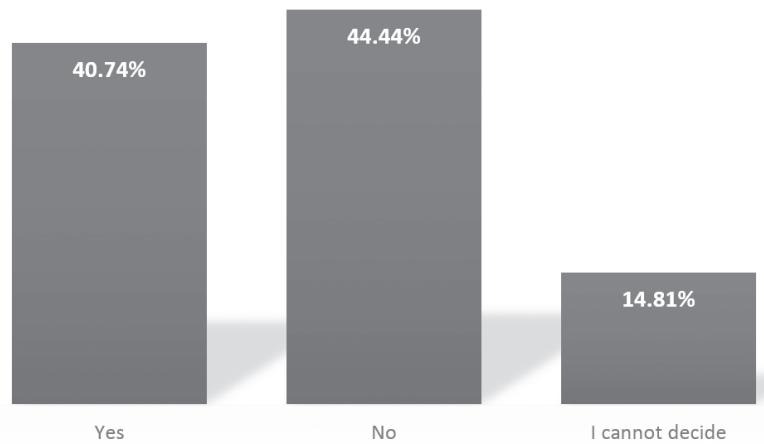

Fig. 7. Lower grade - an incentive for students

Almost half of the respondents are of the opinion, that the lower grade cannot motivate them to strive for better results at tests (44.44\%). Slightly lower is the proportion of students who think the exact opposite (40.74\%). Rather small is the group which cannot decide (14.81\%). The respondents cannot categorically state that the assessment itself can be a motivating factor for putting more effort while gaining more and more knowledge.

The strive for objectifying the results and eliminating the influence of random factors is a reason for the need of specific attention to attempts of cheating (copying, using special devices - phones, watches, pens, etc.). We asked the students about their opinion on cheating during exams (Fig. 8).

Slightly more than half of the inquired think that they would not cheat (59.26\%), around a third admit that they would do so in less important disciplines (29.63\%). Rather small is the proportion of those, who admit, that they would take the chance should they have it (11.11\%).

In order to make the analysis more detailed, we asked students what they would do if they spot a schoolmate cheating during an exam (Fig. 9).
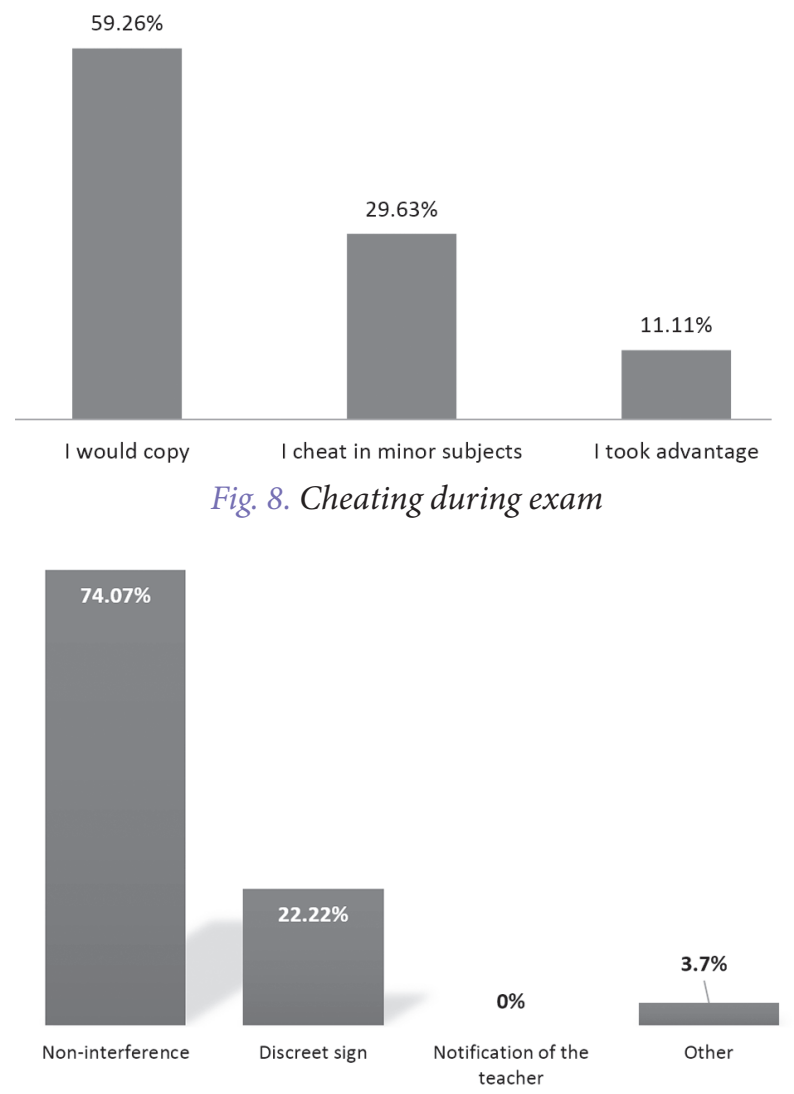

Fig. 9. Copying a colleague

The students' opinion is united around the idea of "non-interference, because of solidarity" (74.07\%), around 1/5 of the students think, that they would make discreet sign to the person cheating (22.22\%). None of the inquired think that it is adequate to notify the examiner about this. It is a rather small proportion where the students gave a different answer - "I would not interfere, but it is not proper." (3.7\%). The response means that we still do not have a strong intolerance built towards cheating and students tend to see silence as a much more acceptable behavior.

The results give us the reason to draw the following conclusions:

1. The students' responses mean that they accept with reservations the assessment as a reflection of received during the course of study knowledge and skills. They think that the assessment itself cannot be a motivating factor, which would lead to more efforts applied by the students when gaining more knowledge. 
2. The form of the exam tests not just the acquired knowledge and skills, but also the individual qualities and characteristics of the examined, which influences the way they perform during exams.

3. There is a need to apply different and various forms, methods and means to the examination process, which objectify the process of control and assessment in relation to the specifics of the practical education and the specifics of working in a real working environment.

4. Students tend to appreciate highly the need of systematic absorption of knowledge and application of constant control during their course of study in the Midwife program.

5. Various forms and methods do not eliminate the influence of random factors completely.

6. There is no evidence of strong intolerance built towards cheating and students tend to see silence as a much more acceptable behavior whilst someone else is trying to cheat.

\section{REFERENCES}

1. Andreev M. Knowledge assessment in high-school. Docimology. Sofia; 1995.

2. Andreev M. Process of study. Didactics. Sofia; 1996.

3. Bizhkov G. Methodology and methods for pedagogy's researches. Sofia; 1995.

4. Gerganov E. Test and Expert knowledge assessment. Availabe at: www.tu-sofia.bg

5. Desev L. Psychology Dictionary. Sofia; 2000.

6. Krasteva A. Students' knowledge and skills assessment aspects.

7. Shanbel A. Assessment of daily school activities. Available at: www.kaminata.net

8. www.diuu.bg 